\title{
(6) OPEN ACCESS \\ Focusing the HIV response through estimating the major modes of HIV transmission: a multi-country analysis
}

\author{
Eleanor Gouws, ${ }^{1}$ Paloma Cuchi, ${ }^{2}$ on behalf of the International Collaboration on \\ Estimating HIV Incidence by Modes of Transmission
}

${ }^{1}$ Evidence, Policy and Innovation Department, UNAIDS, Geneva, Switzerland ${ }^{2}$ HIV Operations Unit, UNITAID, Geneva, Switzerland

\section{Correspondence to} Dr Eleanor Gouws, Evidence, Policy and Innovation Department, UNAIDS, 20 Avenue Appia, Geneva 1211, Switzerland; gouwse@unaids.org

\section{UNAIDS Report 2012}

Guest Editors

Karen Stanecki

Peter D Ghys

Geoff P Garnett

Catherine Mercer

Accepted 24 September 2012

\section{ABSTRACT}

Objective An increasing number of countries have been estimating the distribution of new adult HIV infections by modes of transmission (MOT) to help prioritise prevention efforts. We compare results from studies conducted between 2008 and 2012 and discuss their use for planning and responding to the HIV epidemic.

Methods The UNAIDS recommended MOT model helps countries to estimate the proportion of new HIV infections that occur through key transmission modes including sex work, injecting drug use (IDU), men having sex with men (MSM), multiple sexual partnerships, stable relationships and medical interventions. The model typically forms part of a country-led process that includes a comprehensive review of epidemiological data. Recent revisions to the model are described.

Results Modelling results from 25 countries show large variation between and within regions. In sub-Saharan Africa, new infections occur largely in the general heterosexual population because of multiple partnerships or in stable discordant relationships, while sex work contributes significantly to new infections in West Africa. IDU and sex work are the main contributors to new infections in the Middle East and North Africa, with MSM the main contributor in Latin America. Patterns vary substantially between countries in Eastern Europe and Asia in terms of the relative contribution of sex work, MSM, IDU and spousal transmission.

Conclusions The MOT modelling results, comprehensive review and critical assessment of data in a country can contribute to a more strategically focused HIV response. To strengthen this type of research, improved epidemiological and behavioural data by risk population are needed.

\section{INTRODUCTION}

Significant progress has been made in the HIV response in recent years and programmes are reaching more people and achieving better results than ever before. ${ }^{1}$ However, at a time when the impact is finally becoming evident, international funding for HIV is under threat and it is imperative to invest available resources more strategically. ${ }^{2} 3$

Effective prevention programming and resource allocation requires knowledge of transmission patterns in a country and of the types and frequencies of behaviours that expose people to HIV infection either through unprotected sex, the use of contaminated equipment to inject drugs or through contact with infected blood or blood products. These patterns vary widely between countries and regions, and can change over time within a country because of the natural evolution of the epidemic ${ }^{4}$ and the impact of prevention efforts. ${ }^{5}$

The dynamic nature of the epidemic makes it essential to understand the current distribution of new HIV infections. Direct measurement of HIV incidence and its correlates and determinants through longitudinal follow-up is difficult and expensive, while the use of currently available laboratory assays to detect recent infections still has limitations. ${ }^{6} 7$ Estimates of HIV incidence to date have therefore been dependent mainly on the development and use of mathematical models, some of which have been widely used to inform the planning of country specific programmes. ${ }^{8-13}$

The Modes of Transmission (MOT) model was originally developed by the UNAIDS Reference Group on Estimates, Modelling and Projections and revised and adapted by UNAIDS to help countries estimate the proportion of new infections that may occur through key transmission modes using basic epidemiological and behavioural data as input. Initial applications of the model ${ }^{5} 14$ illustrated the variation in patterns of new infections between countries and suggested that this type of incountry application could be used to inform prevention planning.

Application of the model at country level, dependent on the availability of relevant epidemiological data, has since been recommended as part of the 'Know your Epidemic/Know your Response' initiative by UNAIDS to encourage the use of strategic information to help plan more appropriate and effective responses to the HIV epidemic.

Since 2007, an increasing number of countries have been using the UNAIDS MOT model to estimate the distribution of new adult HIV infections by key modes of exposure. In this paper we discuss the application of the model, compare results between countries in several regions across the world and discuss their use for planning more effective HIV prevention strategies. We also discuss recent revisions and updates to the model.

\section{METHODS AND PROCESS Model}

The MOT model was developed as an easily accessible spreadsheet tool to help countries estimate the proportion of new HIV infections that may occur among adults aged 15-49 years through key transmission modes. The risk populations that are precisely defined by countries include sex workers and their clients, injecting drug users (IDUs), men who have sex with men (MSM), people with multiple 
heterosexual partners in the last year, the spouses of those people with higher risk behaviour, people in stable, mutually faithful heterosexual relationships (including married and cohabiting couples) and people who are at risk of infection through medical injections or blood transfusions. Additional risk populations such as prison populations or transgender women can be included if the required data are available for estimating the risk of infection. The model, described elsewhere ${ }^{14}$ and available at http://www.unaids.org, utilises data on the sizes of risk populations, current HIV prevalence, patterns of risk behaviour and levels of protection against HIV infection (reported use of condoms during sexual contact or sterile equipment during drug injection), together with the transmission probabilities associated with specific risk behaviours. It uses a binomial function to estimate the probability of transmission in each identified risk population. The number of sexual/injecting partners and unprotected sex/injecting acts per partner per year determines the annual number of potential risk encounters in each population group, while the likelihood that any contact will be with an HIV infected partner is determined by the HIV prevalence in the corresponding partner population. The model allows for the modification of the probability of sexual transmission according to the level of male circumcision and the presence of sexually transmitted infections (STI). Estimates of the transmission probabilities for the main transmission modes (heterosexual male-to-female and female-to-male, MSM, IDU, medical injection and blood transfusions) and STI cofactors are derived from the scientific literature. ${ }^{15-19}$

\section{Recent updates}

Given the importance of optimising the allocation of resources in HIV prevention programmes, methods for estimating the sources of new HIV infections in countries with generalised epidemics, including the MOT model, were discussed at the first meeting of the international HIV Modelling Consortium in 2011. ${ }^{20}$ Following recommendations at the meeting, the MOT model has been revised firstly to account for current coverage of antiretroviral therapy and its potential impact on HIV transmission ${ }^{21}$; and secondly to incorporate the calculation of uncertainty bounds as part of the routine application of the MOT model.

A procedure was developed to estimate uncertainty bounds for the MOT analysis in recognition of data limitations and uncertainty associated with the model inputs. ${ }^{22}$ Using plausibility ranges on the key input parameters, prespecified by the user and informed by available data where possible, the model independently and uniformly samples a large number (typically about 1000) of parameter combinations to calculate model outputs from which uncertainty bounds are derived. The total population size and HIV prevalence in the adult population are maintained by allowing the values for the low-risk population to vary according to the proportion of individuals and HIV prevalence in the other risk groups. While this method allows for uncertainty associated with input parameters, it does not fully account for systematic biases in reported behaviours, correlated errors between model parameters or for uncertainty arising from the structural assumptions of the model.

\section{Review of epidemiological data}

One of the key conditions for the application of the MOT model is the availability of country-specific data to inform input parameters. The application of the MOT model in a country should therefore be preceded by a comprehensive review and an assessment of the quality of available epidemiological and behavioural data by risk population. A separate Excel-based tool has recently been developed by UNAIDS to help facilitate the process at country level. It consists of a checklist to assess if required data are available, and various worksheets to help extract and assess the quality of available data by risk population. This tool, referred to as the EPI-MOT tool, with instructions for its use, is available at http://www.unaids.org/en/ dataanalysis/datatools/incidencebymodesoftransmission/.

\section{Country process}

Since 2007, MOT studies have been completed or are underway in more than 30 countries in different regions across the world. The selection of countries to conduct MOT studies has been greatly determined by the availability of essential data, while also considering factors such as country leadership, the incountry capacity to conduct MOT studies and the opportunity for linkage with national planning cycles or evaluation processes.

In the majority of these countries, the MOT analysis has been based on a comprehensive review of HIV epidemiological and behavioural data. The total adult HIV incidence estimated from the MOT model is usually compared with other available estimates (eg, such as those obtained from the Spectrum software) to ensure consistency. The incountry process is typically overseen by a national study team or steering committee with technical support from national and international consultants from various academic institutions for the collection, review and analysis of data. Technical and financial support have been provided by UNAIDS, The World Bank, USAID, PASCA and other organisations.

In several countries the results of the MOT analysis have been compared to National AIDS Spending Assessments (NASA) to assess if the allocation of HIV prevention resources is aligned with the distribution of new HIV infections.

\section{RESULTS}

The country-led MOT studies began in five countries in Southern and east Africa (Lesotho, Kenya, Mozambique, Swaziland and Uganda) in 2007/2008 with the support of UNAIDS and the World Bank. ${ }^{23}$ The results of the MOT analysis together with comprehensive reviews of HIV epidemiological data were summarised in country specific reports and have been presented at several national and international conferences. $^{24-27}$ Other countries in this region, including Rwanda (2009), ${ }^{28}$ Zambia (2008), ${ }^{29}$ South Africa $(2010)^{30}$ and Zimbabwe $(2011)^{31}$ have since completed similar exercises. In 2008, following comprehensive reviews of the HIV epidemics in several countries in West Africa, ${ }^{32}$ MOT studies were conducted in Benin, ${ }^{33}$ Burkina Faso, ${ }^{34}$ Côte d'Ivoire, ${ }^{35}$ Ghana, $^{36}$ Nigeria $^{37}$ and Senegal. ${ }^{38}$ Similar studies followed in Latin America (Peru (2009), ${ }^{39}$ El Salvador (2012), ${ }^{40}$ Nicaragua (2012), ${ }^{41}$ Guyana $\left.(2012)^{42}\right)$, the Caribbean (Dominican Republic $\left.(2009 / 10)^{43}\right)$, the Middle East and north Africa (Morocco (2010), ${ }^{44}$ Iran $(2011)^{45}$ ), eastern Europe (Moldova (2011), ${ }^{46}$ Armenia (2011) ${ }^{47}$ ) and Asia (Philippines, Nepal, Myanmar, Indonesia in 2011). ${ }^{48}$

\section{Model inputs}

Variation within and between regions in the estimated sizes of the different risk populations, as well as in HIV prevalence are shown in tables 1 and 2. Country specific input data are available from country reports and can be accessed at http://www.unaids. org/en/dataanalysis/tools/incidencebymodesoftransmission/ 
Table 1 Risk population size as a percentage of the total number of adult males or females (aged 15-49), expressed as a range for those countries that have conducted MOT within each region

\begin{tabular}{|c|c|c|c|c|c|c|}
\hline & Southern Africa & East Africa & West Africa & Middle East and North Africa & Asia* & Latin America and Caribbean \\
\hline Men & $0-0.7$ & $0.02-0.14$ & $0.09-0.5$ & $0.19-1.14$ & $0.02-0.44$ & $0.02-0.07$ \\
\hline Female sex workers & $0.4-2.0$ & $0.5-2.3$ & $0.6-1.0$ & $0.38-0.75$ & $0.37-0.4$ & $0.7-3.1$ \\
\hline Sex worker clients & $3.0-13.2$ & $2.9-4.0$ & $2.9-17$ & $6.7-7.5$ & $5-5.6$ & $4.1-15.8$ \\
\hline Men having sex with men & $0.1-4.0$ & $0.1-1.0$ & $0.1-0.8$ & $0.5-2.3$ & $1.53-3$ & $2.0-6.0$ \\
\hline Men & $14-38$ & $26-40$ & $14-43$ & $4.5-10$ & $6.9-10$ & $15.3-33.5$ \\
\hline Women & $1.6-17$ & $1.9-18$ & $6-26$ & $1.5-2.4$ & $0.9-1$ & $0.6-16.7$ \\
\hline \multicolumn{7}{|l|}{ Stable relationships } \\
\hline Men & $20-42$ & $25-42$ & $10-33$ & $62-77$ & $43-87$ & $21.5-57.8$ \\
\hline Women & $24-53$ & $29-50$ & $34-54$ & $54-80$ & $49-52$ & $34.9-60.3$ \\
\hline
\end{tabular}

*Based on data from Myanmar and Philippines.

tBased on data from Nicaragua.

MOT, modes of transmission.

\section{Model outputs}

Estimates of the country specific distribution of new infections by MOT are shown with uncertainty bounds in figure 1 . The estimated adult incidence ranged from a low of about 10 per 100000 in eastern European countries to as high as 2000 per 100000 adult population in some Southern African countries. The contribution of individual risk populations to the total number of new infections varied substantially between countries and regions. In Southern and east Africa, the majority of new infections (between $60 \%$ and $95 \%$ ) were estimated to occur in the general heterosexual population, among those people who have multiple sex partners, their regular partners, and those in stable, mutually faithful but discordant relationships. In some countries, notably Kenya and South Africa, substantial numbers of new infections, though with wide uncertainty ranges, were estimated to occur among key populations at higher risk of infection including sex workers and their clients, IDUs, MSM and the prison population in Kenya, contributing jointly to about $33 \%$ of new infections in Kenya and 26\% in South Africa. Sex work, including sex workers, their clients and the regular partners of clients, contributed to between $7 \%$ and $11 \%$ of new infections in Uganda, Swaziland and Zambia. In west Africa, substantial proportions of new infections $(10 \%-32 \%)$ were estimated to occur as a result of sex work, while between $54 \%$ and $72 \%$ were estimated to occur in the general population among those who have multiple sex partners, their spouses and those in stable discordant relationships. In Iran, the largest proportion of new infections were estimated to occur among IDUs and their sexual partners (68\%; uncertainty range 57\%-78\%) while sex work was the main contributor to the epidemic in Morocco, with $43 \%$ (26\%-64\%) of new infections occurring among sex workers, their clients and the regular partners of clients. In Latin American and Caribbean countries, the largest proportion of new infections (from $33 \%$ in Dominican Republic to $56 \%$ in Peru) were estimated to occur among MSM, while substantial proportions of new infections were also estimated to occur among sex workers and their clients, and in the general heterosexual population. In Eastern Europe, while uncertainty bounds are wide, new infections were estimated to be concentrated mainly among IDUs and their sexual partners, accounting for more than $40 \%$ of new infections, and among MSM, accounting for 10\% (2\%-32\%) in Moldova and 24\% (18\%-32\%) in Armenia. Modelling of the epidemic in Myanmar showed significant numbers of new infections (45\%; range 26\%-70\%) occurring among MSM, IDU, sex workers and their clients, while a large proportion of new infections (32\%; range $22 \%-42 \%$ ) were also estimated to occur among people in stable heterosexual relationships, primarily to partners of current and former clients of sex workers, MSM and IDUs. The high level of spousal transmission is characteristic of long running concentrated epidemics in Asia, and highlights the continuing dominance of male risk behaviours in driving transmission in the region.

In the Philippines, the MOT model was applied to data from 2009 and 2011 and figure 1E shows how rapidly the transmission modes can change in low-level and concentrated epidemics. The epidemic in mid-2009 was heavily dominated by

Table 2 Range in HIV prevalence (\%) among adults by risk population, based on those countries that have conducted MOT in each region

\begin{tabular}{llllll}
\hline & Southern Africa & East Africa & West Africa & Middle East and North Africa & Asia* \\
\hline Injecting drug use & $12-54$ & $30-49.5$ & $1.7-6$ & $2-15$ & $0.6-37$ \\
Female sex workers & $48-68$ & $30-47$ & $18.3-38$ & $2-5$ & $0.1-18$ \\
Sex worker clients & $19-45$ & $8.5-21.5$ & $2.4-13.4$ & $0.5-0.5$ & $0.9-4.8$ \\
Men having sex with men & $16.8-40$ & $28-43$ & $10-25$ & $2-2.8$ & $0.014-5.3$ \\
Transgendert & & & & & $0.8-2.2$ \\
Multiple heterosexual relations & $15.5-38$ & $9.6-12.4$ & $1.2-6.2$ & $0.06-0.22$ & $1.2-6.7$ \\
Stable relationships & $12-33$ & $3.9-5.0$ & $0.5-4.5$ & $0.04-0.08$ & $0.01-0.8$ \\
\hline
\end{tabular}

*Based on data from Myanmar and Philippines.

tBased on data from Nicaragua.

MOT, modes of transmission. 
a. Southern Africa
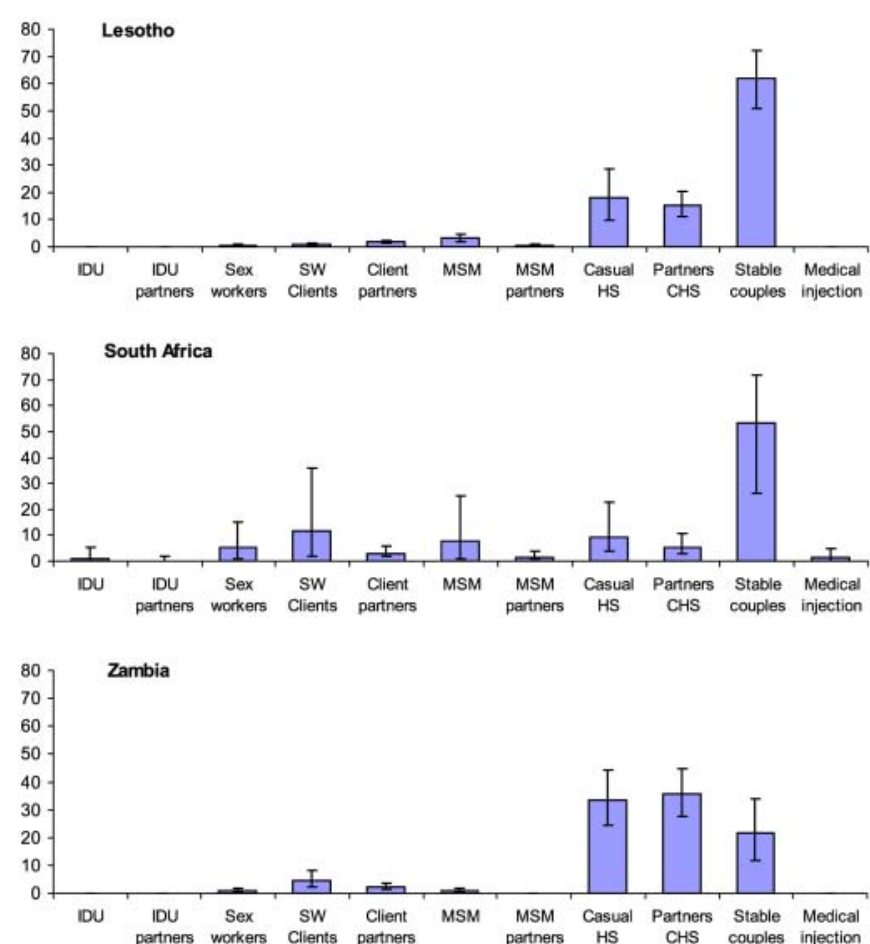

b. East Africa

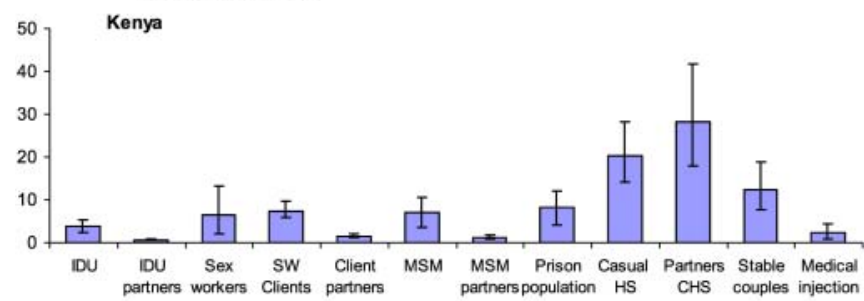

c. Middle East and North Africa

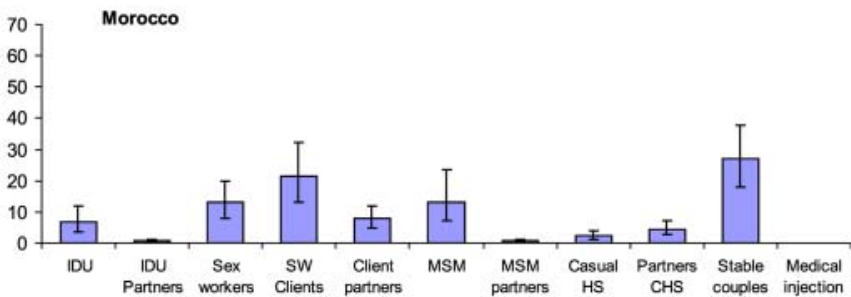

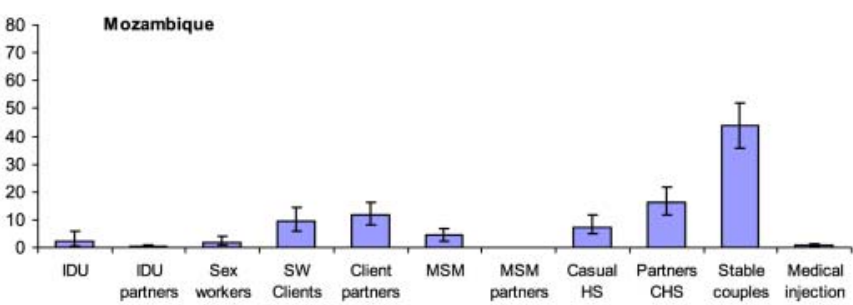
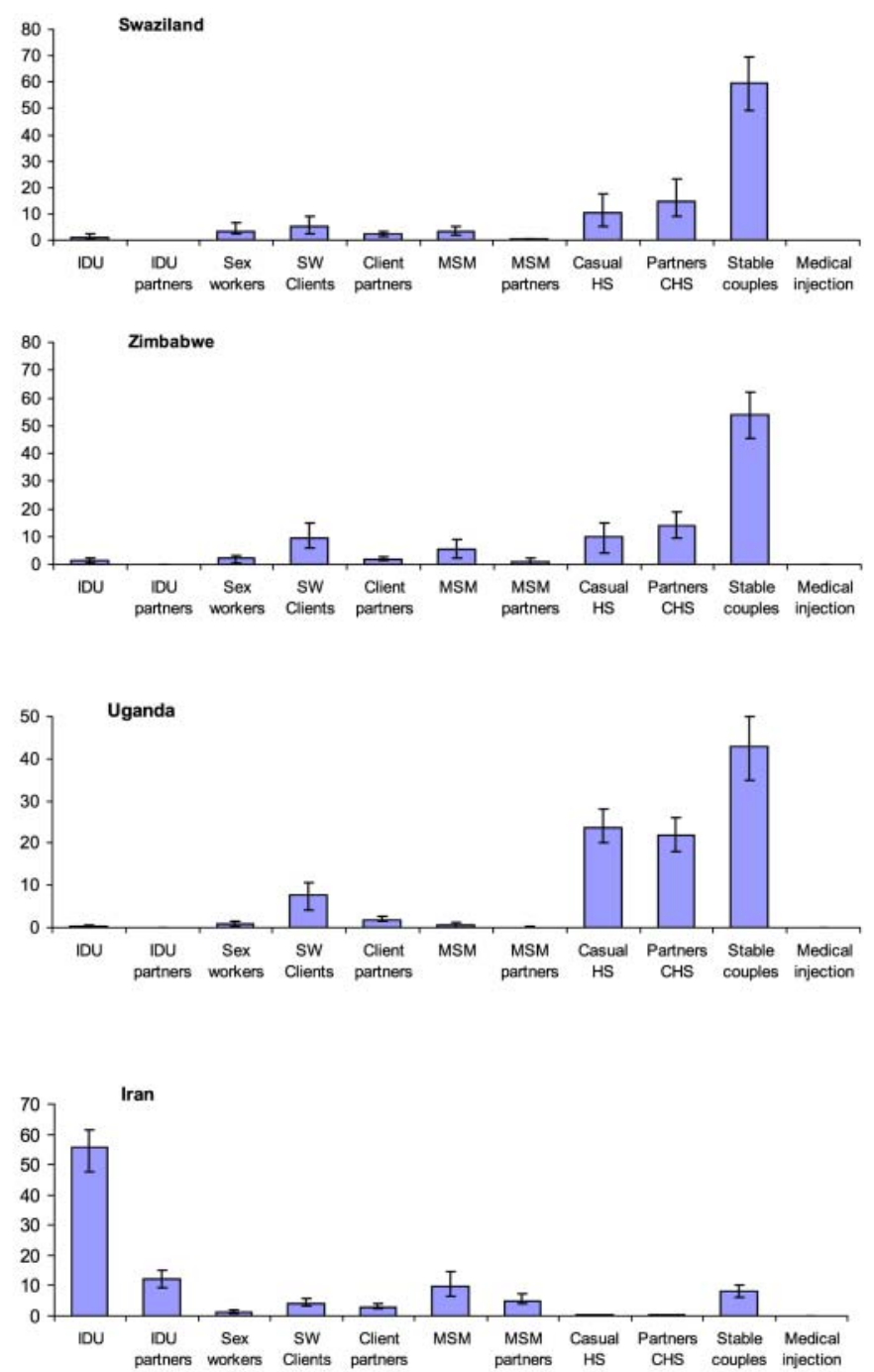

Figure 1 Percent new infections by mode of transmission by country and region (A) Southern Africa (B) East Africa (C) Middle East and North Africa (D) West Africa (E) Asia (F) Eastern Europe (G) Latin America and Caribbean.

MSM, as supported by the rapidly growing proportions of cases reported to the HIV Registry. However, an outbreak of HIV among IDUs in Cebu occurred in late 2009 with prevalence levels rising from $0.59 \%$ to $53 \%$ by mid-2010. By 2011 , the contribution of IDUs to the total number of new adult infections had changed from a small component of the national epidemic to an estimated $36 \%(21 \%-54 \%)$.

\section{Model validation}

Attempts have been made in some countries to validate the results of the MOT studies. In Kenya, an independent assessment of the last 1000 infections by an expert committee in
$2005^{49}$ concluded that sex work (both commercial and transactional), HIV transmission in stable relationships and casual sex alongside intergenerational sex are the key drivers of the epidemic. It also provided warnings of the emergence of IDU in Kenya, and the importance of MSM and the prison population in HIV transmission. These early results were consistent with the application of the MOT model in $2006^{14}$ and in $2008 .{ }^{24}$ In Myanmar, the MOT results were compared to those of the Asian Epidemic Model (AEM) and showed differences that were largely traceable to the transmission probabilities used in the two models. ${ }^{48}$ In the AEM the transmission probabilities are usually adjusted so that predicted model prevalence based 
d. West Africa
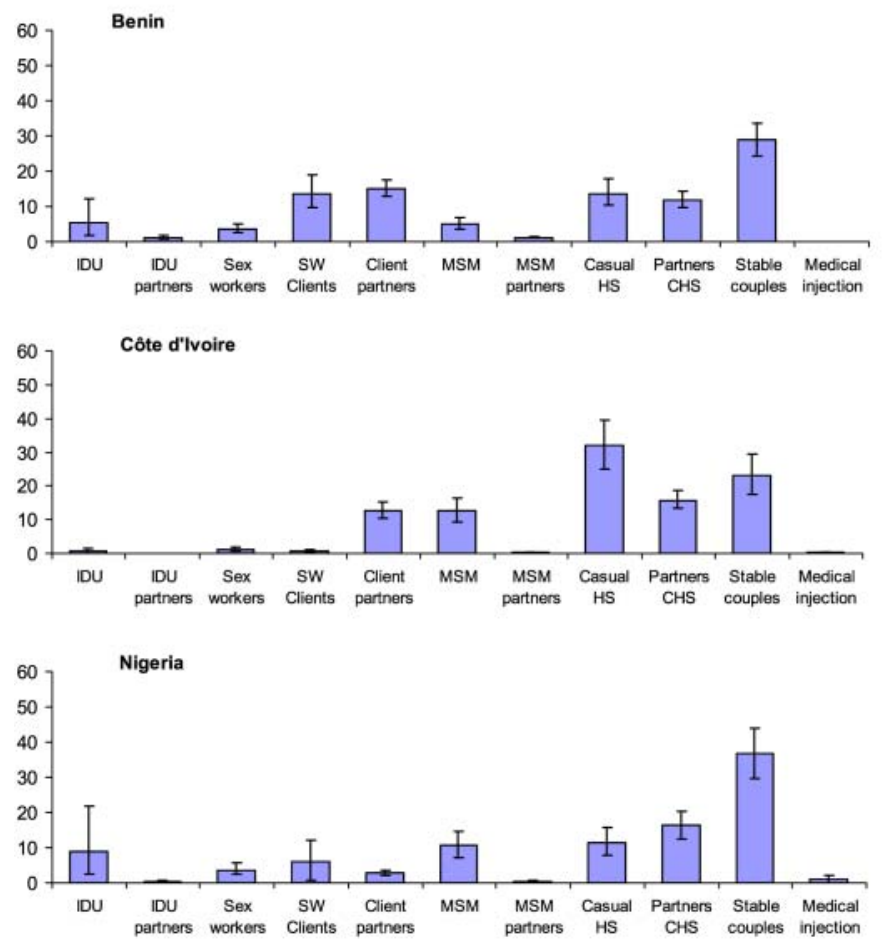

e. Asia
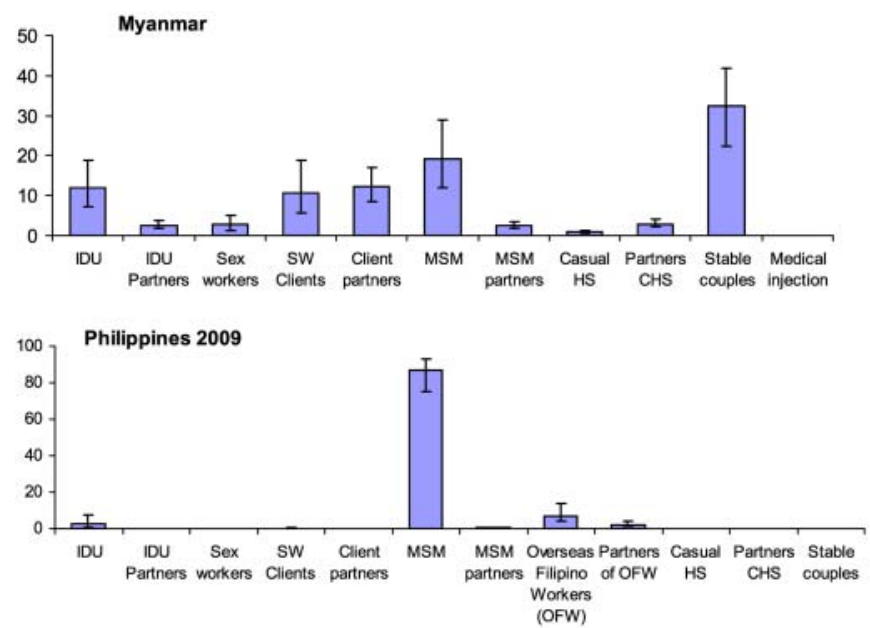

Figure 1 (Continued)

on local behavioural data matches locally observed prevalence trends from surveillance over a number of years, while the MOT utilises one set of default transmission probabilities. The AEM often requires larger transmission probabilities than those used in the MOT model to match observed prevalence patterns, which may reflect the impacts of primary HIV infection in high turnover populations. In Morocco, notified HIV/AIDS cases confirmed the dominance of the heterosexual mode of HIV transmission. ${ }^{44}$

\section{Response to the epidemic, allocation of resources and country experiences}

The MOT studies, including the epidemiological reviews and MOT modelling, have been positively received by policy makers and programme implementers and in several countries
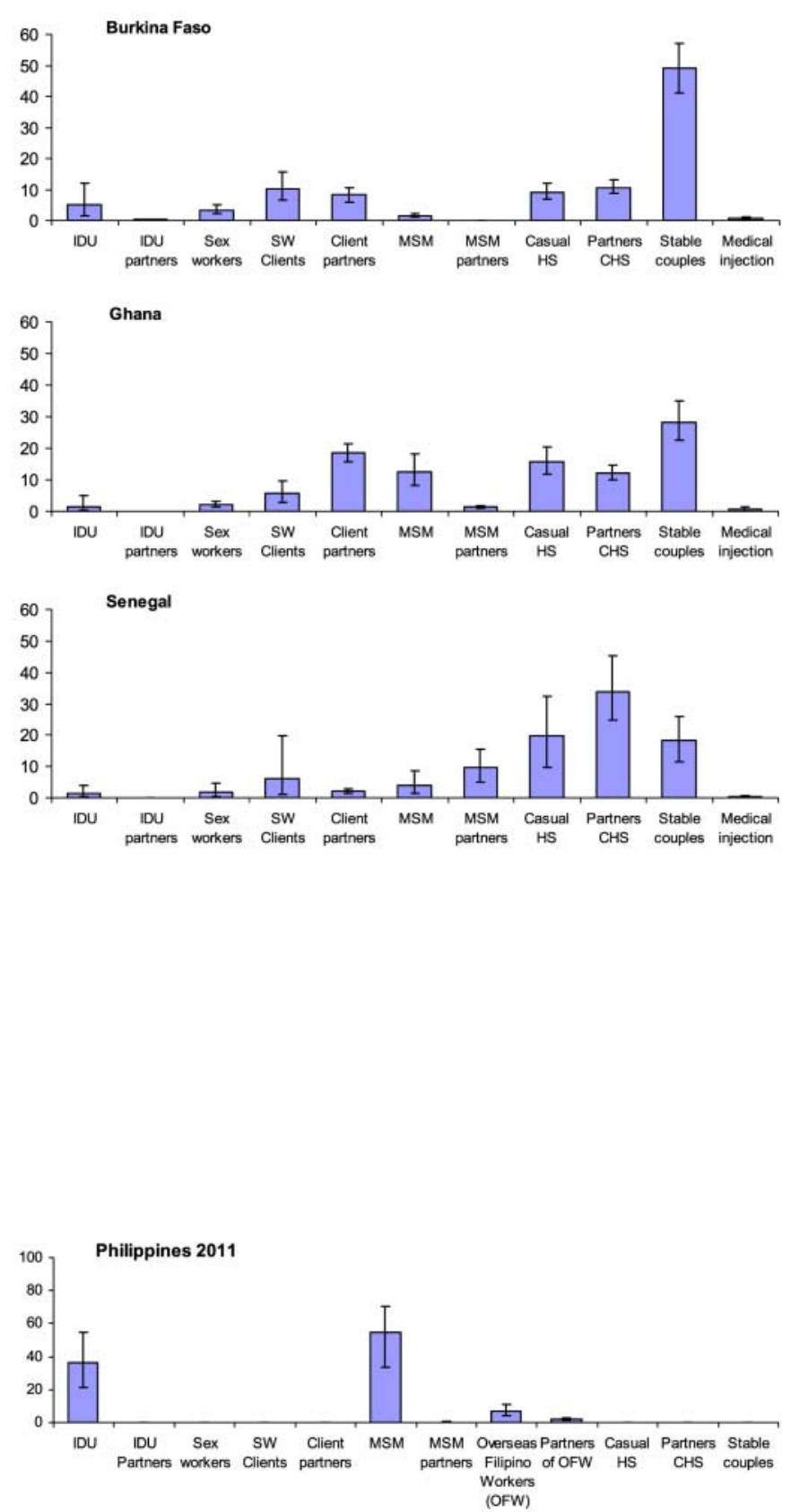

the results have been considered in national response planning and in grant applications.

In Morocco, the comparison of the distribution of new HIV infections with prevention expenditures using the NASA showed that while key populations (sex work, MSM and IDU networks) were estimated to account for about two thirds of all new HIV infections, less than one third of HIV/AIDS prevention expenditures were directed towards them (figure 2). ${ }^{44} 50$ However, these results were considered in the planning of the 2012 to 2016 National Strategic Plan, which shows significant revisions and proposals to allocate $63 \%$ of AIDS resources towards prevention among key populations. ${ }^{51}$

In west Africa, comparison of MOT results with NASAs showed that sex workers and clients, MSM and IDUs contributed to an estimated $20 \%$ of new infections in Burkina Faso, 
f. Eastern Europe

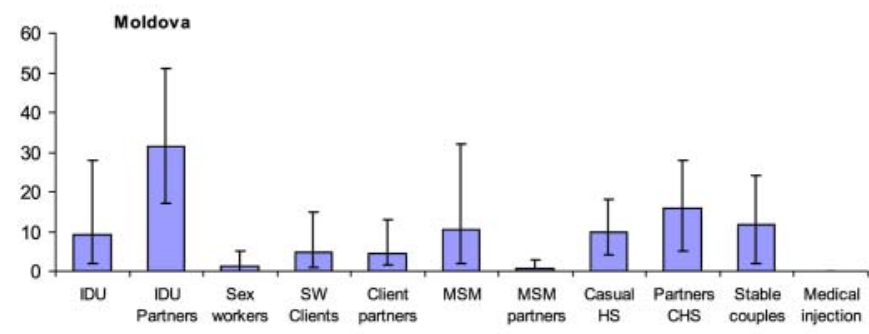

g. Latin America and Caribbean
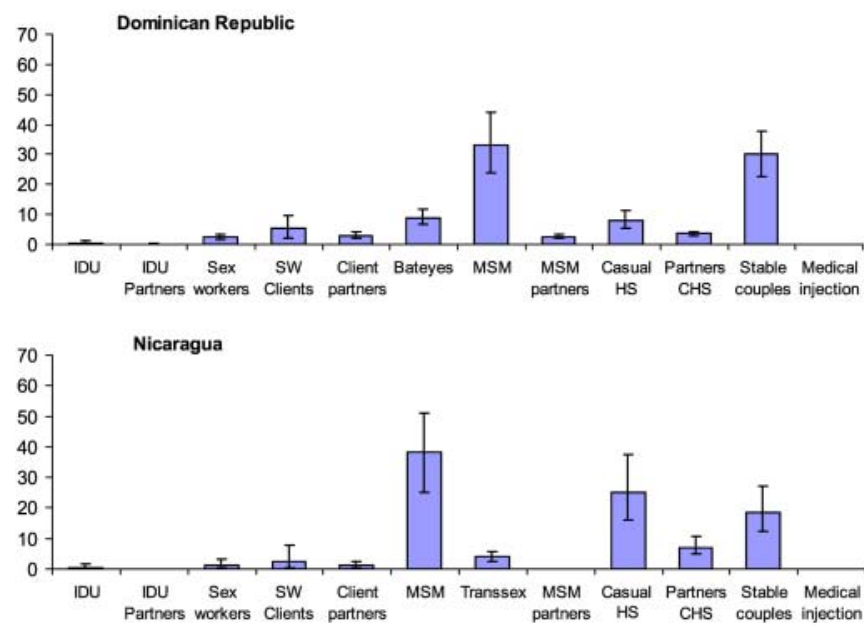

Figure 1 (Continued)

$15 \%$ in Côte d'Ivoire and 22\% in Ghana, while only 1.7\%, 0.4\% and $0.24 \%$ of prevention expenditure, respectively, were allocated to these groups. ${ }^{52}$ Following the MOT studies in this region, there has been an increased focus on key populations. In Benin, more resources are being allocated to sex workers and their clients, and in Ghana, Côte d'Ivoire and Burkina Faso the new national strategic plans propose increases in the budget allocation for prevention among key populations.

The MOT exercise in Kenya resulted in an increased focus on key populations including MSM, prison populations, IDUs and sex workers and their clients. The results guided the 2009/2010 to $2012 / 2013$ national strategic plan $^{53}$ and led to significant funding increases for services targeting key populations. At the same time, the results emphasised the importance of transmission within couples.

In Nepal, the MOT process was challenging because of data limitations, but the process itself encouraged more careful review of the data and reassessment of the contribution of migrants to the national epidemic. In the Philippines, the MOT study was particularly timely as it coincided with an explosive epidemic among IDUs in Cebu and MSM nationwide. While the MOT process promoted a closer look at recent epidemiological data, it was also considered a useful advocacy tool for illustrating to local leaders and programme managers the potential impact that focused prevention efforts in a population such as IDUs could have on the epidemic. ${ }^{48}$ In Myanmar and Indonesia, both the MOT workbook and AEM were applied to analyse the MOT; and both countries used the MOT findings from AEM to inform national strategic planning.

An important contribution of the MOT results has been the identification of data gaps and limitations and has led several
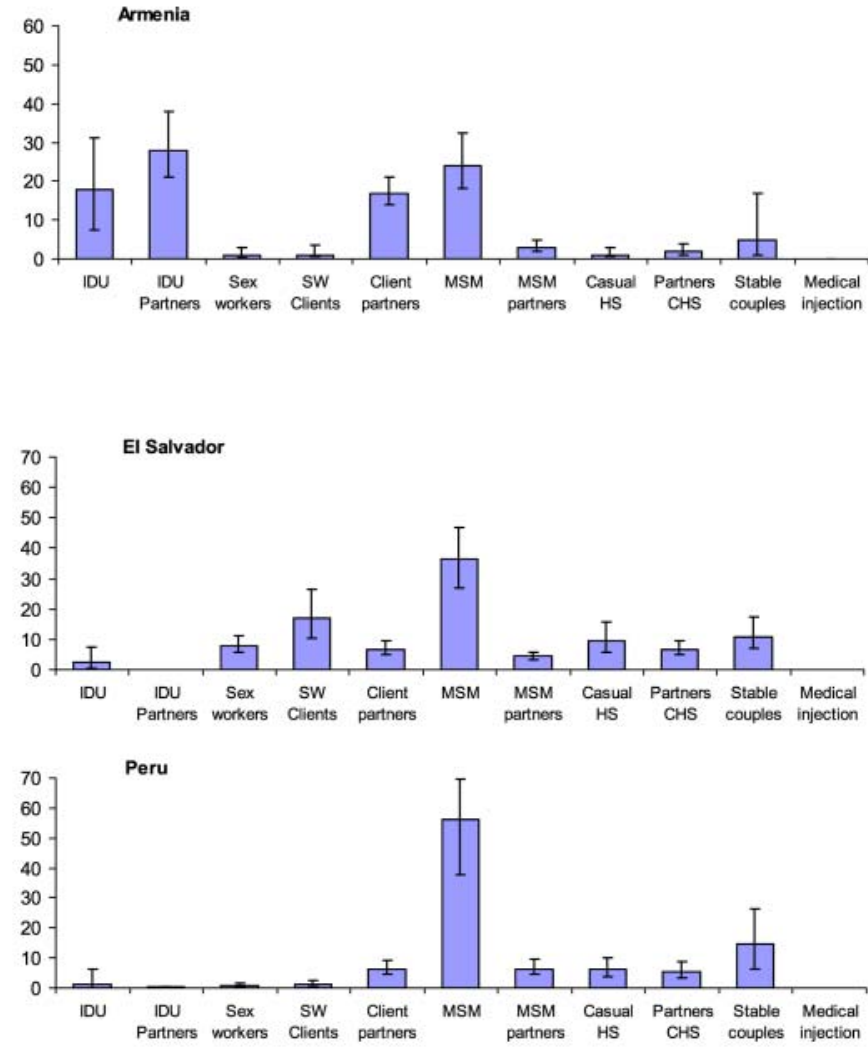

countries to plan further data collection, improve surveillance and carry out studies on key populations. For example, in Moldova the MOT findings were considered in a data triangulation process in preparation for the national AIDS programme; efforts to collect more data among key populations have been proposed in grant applications in Ghana; while studies have been initiated in Zimbabwe to estimate the sizes of key populations. In El Salvador, the completion of the MOT study coincided with the preparation of the national research plan, and the knowledge gaps identified during the MOT process led to recommendations for further data collection, specifically on sexual behaviour and HIV prevalence among key populations.

In Guyana, application of the newly developed EPI-MOT tool to assess availability and quality of epidemiological data helped the country to identify data limitations and problems. Based on this assessment the country decided not to immediately conduct the MOT modelling but to first collect more data, and to improve HIV surveillance and data quality. ${ }^{42}$

\section{DISCUSSION}

A focused and strategic approach to the HIV response should be based on a clear understanding of the spatial and temporal variation of HIV transmission patterns and associated risk behaviours. The 'Know your Epidemic/Know your Response' efforts are intended to help countries become more systematic in their prevention approaches by using strategic information to inform programme planning and decisions regarding resource allocation. The proposed process includes a comprehensive review of available epidemiological data, analysis to determine the distribution of new infections by MOT, and a comparison of current prevention responses and resource allocation with 
Figure 2 Comparison of modes of transmission and NASA results in Morocco. (A) Distribution of new HIV infections in 2009 (\%); (B) HIV prevention spending in $2008(\%)$.
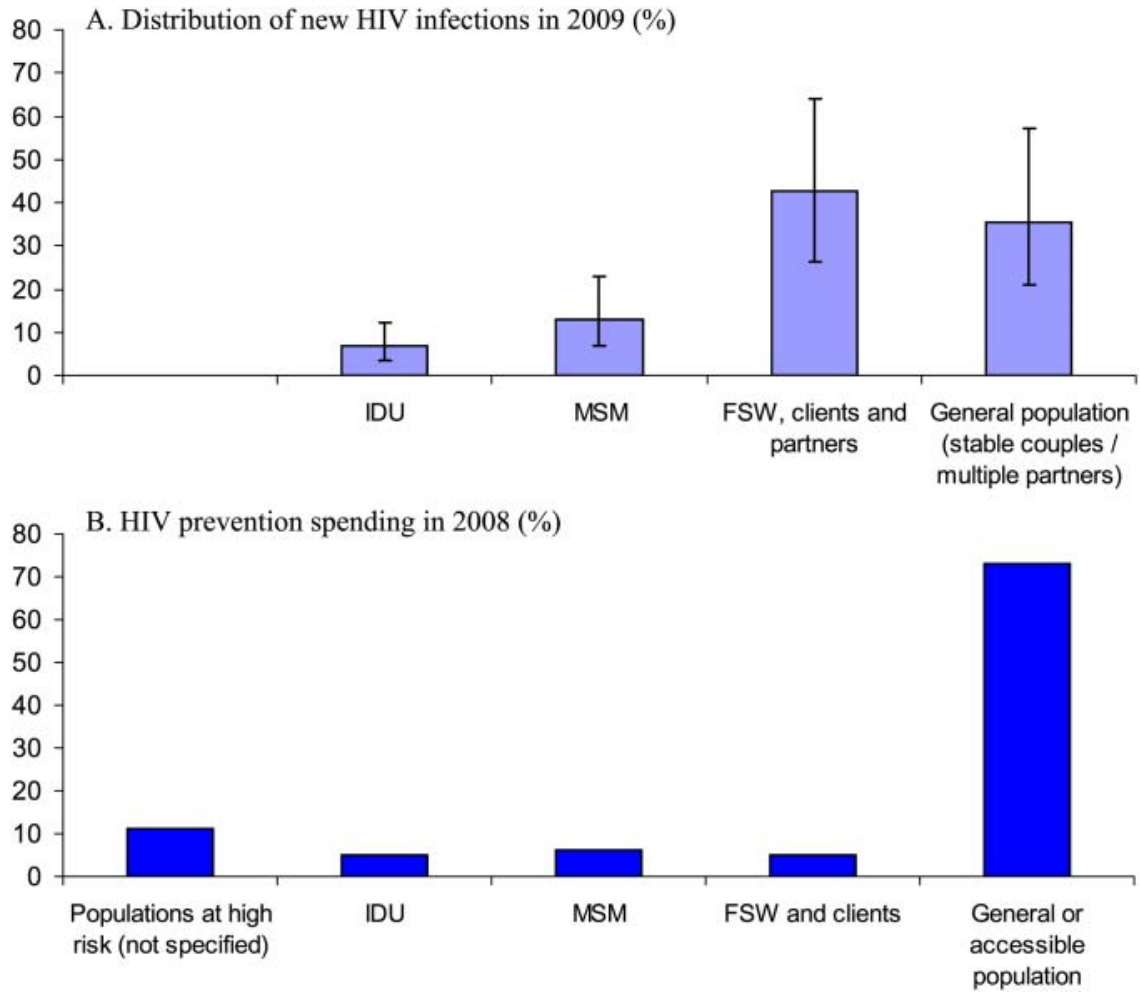

the modelled HIV incidence estimates. The MOT analysis has constituted a vehicle through which this approach has been considered, developed and implemented.

To date, MOT analyses have been conducted or are underway in more than 30 countries worldwide. Results for those countries that have successfully completed MOT exercises are summarised in this article and show wide variation between and within regions. In sub-Saharan Africa, application of the MOT model has shown that the majority of new infections are likely to occur in the general population among stable, discordant couples and those individuals who have multiple sex partners. Priority should therefore be given to those interventions and combinations of interventions, specific to the local context, which may have the biggest impact on the epidemic including the promotion of medical male circumcision in high HIV prevalence countries, expanding HIV testing and counselling services and expanding access to antiretroviral therapy for treatment and prevention. It should also continue to promote safe sexual behaviour including the reduction of multiple sexual partners and high levels of condom use, and strengthen comprehensive HIV programmes for sex workers.

In Latin America, prevention efforts should continue to focus on reducing risky behaviour among MSM, while efforts in Morocco, North Africa, should focus greatly on commercial sex networks. These programmes should include targeted communication, education and condom programming, as well as community mobilisation. In eastern Europe and the Middle East, reducing new infections among IDUs should be essential, by providing sterile drug injecting equipment and drug substitution therapy. Access to antiretroviral therapy should be promoted in all key populations to ensure good health outcomes and to reduce HIV transmission, while it is essential that programme activities for key populations be complemented by increased support for the protection of human rights, outreach to marginalised populations and for the reduction of stigma. ${ }^{2}$
The MOT results in Asia confirm the continuing focused nature of the epidemics in the region, with new infections concentrated in key populations and their immediate sexual partners. However, there is wide variation in the contribution of the different groups to the HIV epidemics in the region and the situation can change rapidly over a short time, as was illustrated in the Philippines. ${ }^{11}$ This diversity can be explained by variations in the size of key populations, behavioural factors, biological factors, timing of the introduction of HIV and the level and effectiveness of responses in key populations. ${ }^{54}$ As a consequence, the focus of effective prevention responses can vary greatly and careful local assessments are needed to guide those responses.

While HIV remains concentrated in key populations in most countries in Asia, the contribution of transmission to spouses of those currently or formerly at higher risk (clients of sex workers, MSM, IDU) has increased in several countries in recent years. In Myanmar, for example, while a strong national response has stabilised HIV among sex workers and their clients, ${ }^{48}$ it is estimated that about one third of new infections may be occurring among people in stable relationships. However, prevention responses focused on these discordant couples in long-running Asian epidemics remain weak and an is an outgrowth of the continued focused nature of risk in Asia and does not call for a shift from focused prevention efforts to general population efforts. ${ }^{3}$

The limitations of the model have been discussed in depth at meetings ${ }^{20}$ and have been documented in several scientific articles, ${ }^{14} 5556$ country and regional reports. ${ }^{48} 52$ These have been considered seriously and have already led to revisions in the MOT model and the process. It includes limitations related to the structure of the model, the availability and quality of empirical data used in the model, and the interpretation of results. ${ }^{55}$ Briefly, the model does not take into account the heterogeneity in behaviour within risk populations or overlapping risk important prevention gap. It should be noted that this pattern 
behaviours; it does not allow for variation in the probability of transmitting HIV by stage of infection; and as a static model it does not take account of historical trends in prevalence and changes in individual or population level behaviour over time.

Limitations in the availability and quality of required data in countries are of particular concern. Data on key populations are often limited and difficult to obtain and studies conducted among these populations, particularly in countries where such populations are stigmatised or marginalised, are most often not representative of the entire population. In some countries the size of the stable heterosexual population is assumed as the 'left-over' after all the other population group sizes have been estimated and the incidence contribution could be inflated if unknown risk groups or behaviours are not accounted for. Furthermore, the reliability of self-reported data on risk behaviour can be questionable and the extent of under-reporting or over-reporting is often not known. Some research studies have shown that responses to household survey questions about visiting sex workers or having multiple partners under-report the true behaviours. ${ }^{57}$ To the extent that models rely on this data they may underestimate the proportion of new infections occurring among these populations. Because of limited data at subnational or provincial level, the model is usually conducted at the national level and hence subnational variation in transmission patterns is not captured.

Some of the model limitations have been addressed and the most recent version of the model allows the user to include information on the use of antiretroviral therapy to account for its effect on reducing HIV transmission. Uncertainty analysis has been integrated with the standard model to assist with interpretation of results and it is now recommended that results always be presented with uncertainty bounds. In addition, UNAIDS has developed a new tool to help countries assess the availability and quality of epidemiological and behavioural data and to help users better judge the reliability of results. Where data availability and quality are not adequate, countries are advised to first collect more data or conduct further studies before application of the MOT model.

Following the international Modelling Consortium meeting in 2011, further research is being conducted on particular aspects of the model, including the influence of assumptions about hierarchies of risk in populations, and the influence of the static nature of the existing model. ${ }^{20}$

One of the advantages of the MOT analysis is that it usually forms part of a country-owned, multistage process which includes a comprehensive review of data and, where possible, a comparison with response data. The MOT model was designed as a simple and transparent model and can be applied across a range of epidemiological settings. The model can also be used as an advocacy tool to show the influence of specific interventions such as behavioural change, voluntary medical male circumcision and use of antiretroviral therapy on the epidemic, or to highlight areas of potential improvement in the prevention response. Importantly, it helps to build capacity in countries and it brings together experts and stakeholders to critically review available data, to identify limitations or biases in the data and to identify and fill key gaps in their understanding of the epidemic and the contribution of specific risk populations. This process is central to any attempt to estimate the modes of HIV transmission. In this regard the indirect benefits of the MOT analysis and the process in several countries have exceeded their direct technical value in mapping the HIV transmission by mode of exposure.

The majority of countries that have conducted MOT studies have considered them useful. An outcome evaluation conducted in east and Southern Africa concluded that the MOT studies achieved their main purpose of reinvigorating thinking about epidemic dynamics, HIV prevention and improving the HIV response. ${ }^{58}$ In most instances the process was well constructed and involved extensive incountry and international consultation with close involvement or coordination from the National AIDS Councils, among other governmental or nongovernmental organisations and academic institutions. Both the epidemiological reviews as well as the modelling processes involved high level expertise and experience in countries.

The results of the MOT studies have been considered in national planning efforts and grant applications in several countries. In subSaharan Africa, the role of certain key populations in the epidemics in some countries, notably in Kenya and some west African countries, has been made more prominent and these groups are now receiving more recognition in national strategic plans. In all countries the MOT analysis resulted in the recognition of data limitations and in particular, the need for improved data on key populations and risk behaviour. In several countries it has already led to attempts to improve the quality of available data sources or to collect further information through, for example, improved surveillance or size-estimation studies.

Further MOT studies are underway in various countries. Better data are still needed, further refinements to the model could be made, the models must be applied carefully and rigorously, and the model outputs must be triangulated with other sources of information on HIV transmission. The results of these studies could contribute significantly to understanding national HIV epidemics, allocating resources more efficiently and implementing a more effective HIV response.

\section{Key messages}

- Modes of HIV transmission and associated risk behaviours vary greatly between countries and regions and can change over time.

- Careful and rigorous assessment of the modes of HIV transmission, combined with a comprehensive review and critical assessment of epidemiological and behavioural data, can contribute to a better understanding of national epidemics, to a more strategic HIV response and to more efficient allocation of resources.

- There is a clear and urgent need for improved data on key populations and on risk behaviour in order to improve the quality of the results of future analyses.

\section{Collaborators \\ International Collaboration on Estimating HIV Incidence by Modes of Transmission \\ UNAIDS Geneva (MOT): Eleanor Gouws, Paloma Cuchi, Peter Ghys UNAIDS Geneva (NASA): Benjamin Gobet}

Asia UNAIDS Regional Office: Amala Reddy. International consultants: Tim Brown, Virginia Loo, Wiwat Peerapatanapokin, Tobi Saidel, Nalyn Siripong

National study teams: Myanmar: Aye Aye Sein, San Hone, Khin Zarli Aye, Markus Bühler; Philippines: Genesis Samonte, Noel Palaypayon, Zimmbodilion Y Mosende

Indonesia: Asep Kurniawan, Victoria Indrawati, Wenita Indrasari, Asep Eka Nur Hidayat, and Lely Wahyuniar; Nepal: Deepak Karki, Amdo Kumar Poudyal, Alankar Malviya. 
Eastern Europe and Central Asia UNAIDS Regional Office: Lev Zohrabyan. International consultants: Kelsey Case

National study teams: Moldova: Otilia Scutelniciuc, Valeriu Plesca, Stela Bivol, Alexandrina lovita; Armenia: Samvel Grigoryan, Arshak Papoyan.

Latin America and Caribbean UNAIDS Regional Office: Marjolein Jacobs. International consultants: Annick Borquez, Juan F Vesga

National study teams: Dominican Republic: Yordana Doloros, Tessie Caballero Vaillant, Elizabeth Conklin-Ballester; El Salvador: Ana Isabel Nieto, José Salvador Sorto, Herbert Betan court, Marta Aurelia Martinez; Peru: Jorge Alarcon, Monica Pun, Luis Suarez, Romina Tejada, Cesar Gutierrez; Guyana: Otilia St Charles, Rosalinda Hernandez; Nicaragua: Enrique Beteta Acevedo, Luis Carballo Palma, José Medrano, Dina Soza, Ofelia Chicas.

Middle East and North Africa UNAIDS Regional Office: Hamidreza Setayesh. International consultants: Laith Abu-Raddad

National study teams: Morocco: Ghina R Mumtaz, Ahmed Zidouh, Houssine El-Rhilani, Aziza Bennani, Kamal Alami; Iran: Maryam Nasirian, Aliakbar Haghdoost, Fardad Doroudi.

Southern and East Africa UNAIDS Regional Office: Susan Kasedde (now UNICEF). International consultants: Mark Colvin, John Stover. The World Bank: Nicole Fraser. National study teams: Kenya: Lawrence Gelmon, Patrick Kenya, Francis Oguya, Boaz Cheluget, Girmay Haile; Lesotho: Motlalepula Khobotlo, Relebohile Tshehlo, John Nkonyama, Mikaela Hildrebrand; Mozambique: Mauricio Cysne, Mari Luntamo; South Africa: Reshma Kassanjee, Alex Welte, Henry Damisoni; Swaziland: Sibusiso Mngani, Happiness Mkhatshwa, Tyrone Lapidos, Thandi Khumalo, Sanelisiwe Tsela, Nhlanhla Nhlabatsi, Helen Odido; Uganda: Fred Wabwire-Mangen, Martin Odiit, Wilfred Kirungi, David Kaweesa Kisitu, James Okara Wanyama; Zambia: Harold Witola, Celestine Buyu, Michael Gboun; Zimbabwe: Nomasomi Mpofu, Victoria James, Amos Milanzi, Masauso Nzima.

West Africa UNAIDS Regional Office: Alliou Assani. International consultants: John Stover, Annick Borquez, Catherine Lowndes, Michel Alary. World Bank: Juliana Victor-Ahuchogu

National teams: Benin: Alphonse Guedeme, Gatien Ekanmian, Justin Toussou; Burkina Faso: Frederic Kintin, André Kaboré, Jean-Baptiste Gatali; Côte d'Ivoire: Karim Seck, Eugene Eba, Pascal Eby; Ghana: William Bosu, Kenneth Zeboah, Rangaiyan Gurumurthy; Nigeria: Joseph Nnorom, Fajemisin Oluwole, Job Sagbohan; Senegal: Karim Seck.

Contributors Both authors contributed to the overall design and management of the modes of transmission process in various regions across the world. EG wrote the first draft of the paper. Both authors contributed to the analysis, interpretation and writing of the final manuscript. Country and regional collaborators coordinated the country specific studies, analyses and reports, and provided comments on the final paper.

\section{Competing interests None.}

Provenance and peer review Commissioned; externally peer reviewed.

\section{REFERENCES}

1. UNAIDS. Together we will end AIDS. Geneva: UNAIDS, 2012.

2. Schwartländer B, Stover J, Hallett T, et al. Towards an improved investment approach for an effective response to HIV/AIDS. Lancet 2011;377:2031-41.

3. UNAIDS Regional Support Team for Asia and the Pacific. Redefining AIDS in Asia. Crafting an effective response. Report of the Commission on AIDS in Asia. India, 2008.

4. Hallett T. Monitoring HIV epidemics: declines in prevalence do not always mean good news. AIDS 2009:23:131-2.

5. Pisani E, Garnett GP, Brown T, et al. Back to basics in HIV prevention: focus on exposure. Br Med J 2003:326:1384-87.

6. Mastro TD, Kim AA, Hallett T, et al. Estimating HIV incidence in populations using tests for recent infection: issues, challenges and the way forward. J HIV AIDS Surveill Epidemiol 2010;2:1-14.

7. Busch MP, Pilcher CD, Mastro TD, et al. Beyond detuning: 10 years of progress and new challenges in the development and application of assays for HIV incidence estimation. AIDS 2010;24:2763-71.

8. Stover J, Johnson P, Hallett T, et al. The Spectrum projection package: improvements in estimating incidence by age and sex, mother-to-child transmission, HIV progression in children and double orphans. Sex Transm Infect 2010:86(Suppl 2):ii16-21.

9. Brown T, Bao L, Raftery AE, et al. Modelling HIV epidemics in the antiretroviral era: the UNAIDS estimation and projection package 2009. Sex Transm Infect 2010;86 (Suppl 2):ii3-10.

10. Brown T, Peerapatanapokin W. The Asian Epidemic Model: a process model for exploring HIV policy and programme alternatives in Asia. Sex Transm Infect 2004;80 (Suppl 1):i19-24

11. USAID. From analysis to action. The A2 approach. Family Health International, East-West Centre. RTI International and Futures Group International, 2009 http:// www.fhi360.org/NR/rdonlyres/e5rj4rwqqmegh3gu5ekk4z2m3yzaeor35i4lau6nogwx
3clforycasrdvsm5sfaiw5a3w4ixztg6wm/fromanalysistoactiontheA2approach.pdf (accessed 18 Oct 2012)

12. Williams B, Gouws E, Wilkinson D, et al. Estimating HIV incidence rates from age prevalence data in epidemic situations. Stat Med 2001;20:2003-16.

13. Vickerman P, Foss AM, Pickles $M$, et al. To what extent is the HIV epidemic in southern India driven by commercial sex? A modelling analysis. AIDS 2010;24:2563-72.

14. Gouws E, White PJ, Stover J, et al. Short term estimates of adult HIV incidence by mode of transmission: Kenya and Thailand as examples. Sex Transm Infect 2006;82(Suppl 3):iii51-5.

15. Gray RH, Wawer MJ, Brookmeyer R, et al. Probability of HIV-1 transmission per coital act in monogamous, heterosexual, HIV-1-discordant couples in Rakai, Uganda. Lancet 2001;357:1149-53

16. Baggaley R, Boily MC, White RG, et al. Systematic review of HIV-1 transmission probabilities in absence of antiretroviral therapy. London: Imperial College, 2004.

17. Baggaley RF, Boily MC, White RG, et al. Risk of HIV-1 transmission for parenteral exposure and blood transfusion: a systematic review and meta-analysis. AIDS 2006;20:805-12.

18. Baggaley RF, White RG, Boily MC. HIV transmission risk through anal intercourse: systematic review, meta-analysis and implications for HIV prevention. Int J Epidemiol 2010;39:1048-63.

19. Fleming DT, Wasserheit JN. From epidemiological synergy to public health policy and practice: the contribution of other sexually transmitted diseases to sexual transmission of HIV infection. Sex Transm Infect 1999;75:3-17.

20. The HIV Modelling Consortium. Report for Topic Meeting One: Sources of Infections and National Intervention Impact Projections. Montreux, Switzerland, 2011. http://www.hivmodelling.org/projects/sources-hiv-infection (accessed 18 0ct 2012).

21. Cohen MS, Chen YQ, McCauley M, et al. Prevention of HIV-1 infection with early antiretroviral therapy. N Engl J Med 2011;365:493-505.

22. Stover J, Borquez A. Uncertainty estimation for the Modes of Transmission model 2009 (unpublished UNAIDS report)

23. Colvin M, Gorgens-Albino M, Kasedde S. Analysis of HIV prevention response and modes of HIV transmission: The UNAIDS-GAMET supported synthesis process (summary report). Southern and East Africa: UNAIDS, Regional Support Team, 2008.

24. Gelmon L, Kenya P, Oguya F, et al. Kenya HIV prevention response and modes of transmission analysis. Nairobi: Kenya National AIDS Control Programme, UNAIDS, the World Bank Global AIDS M\&E Team (GAMET), 2009.

25. Khobotlo M, Tshehlo R, Nkonyana J, et al. Lesotho: analysis of prevention response and modes of Transmission Study: Lesotho National AIDS Commission. Maseru: UNAIDS, World Bank Global AIDS MGE Team (GAMET), 2009.

26. Mngadi S, Fraser N, Mkhatshwa $\mathrm{H}$, et al. Swaziland HIV prevention response and modes of transmission analysis. Final Report: National Emergency Response Council on HIVIAIDS. Mbabane: UNAIDS, World Bank Global AIDS M\&E Team (GAMET), 2009

27. Wabwire-Mangen F, Odiit M, Kirungi W, et al. Uganda: HIV modes of transmission and prevention response analysis. Kampala: Uganda AIDS Commission, UNAIDS, 2009.

28. Asiimwe A, Koleros A, Chapman J. Understanding the dynamics of the HIV epidemic in Rwanda. Modelling the expected distribution of new HIV infections by exposure group. Rwanda: National AIDS Control Commission of Rwanda, Measure Evaluation. 2009

29. Mulenga 0, Witola $\mathrm{H}$, Buyu $\mathrm{C}$, et al. Zambia HIV prevention response and modes of transmission analysis: Zambia National HIVIAIDS/STI/TB Council. Lusaka: UNAIDS, World Bank Global HIV/AIDS Program, 2009.

30. South African Centre for Epidemiological Modelling and Analysis. The modes of transmission of HIV in South Africa. The HIV incidence modelling component of the South African know your epidemic, know your response synthesis. Stellenbosch: SACEMA, 2009

31. Zimbabwe National AIDS Council. Zimbabwe analysis of HIV epidemic, response and modes of transmission: National AIDS Council. Harare: Zimbabwe Ministry of Health and Child welfare, The World Bank, UNAIDS, 2010.

32. Lowndes C, Alary M, Belleau M, et al. West Africa HIVIAIDS epidemiology and response synthesis. Characterisation of the HIV epidemic and response in West Africa: implications for prevention. Washington DC: The World Bank Global HIV/AIDS Program, 2008.

33. Guedeme A, Ekanmian GK, Toussou JY, et al. Rapport de l'Etude sur les Modes de Transmission du VIH au Benin: CNLS. Cotonou, UNAIDS, 2009

34. Kintin DF, Kaboré A, Gatali JB, et al. Modes de transmission du VIH en Afrique de I'Ouest: analyse de la distribution des nouvelles infections par VIH au Burkina Faso et recommandations pour la prévention: CNLS. Burkina Faso: UNAIDS, 2009.

35. Seck K, Eba KE, Eby P, et al. Modes de transmission du VIH en Afrique d'Ouest: analyse de la distribution des nouvelles infections par le VIH en Côte d'Ivoire: recommandations pour la prévention. Côte d'Ivoire: Ministère de la Lutte contre le SIDA, UNAIDS, 2009.

36. Bosu WK, Yeboah K, Gurumurthy R, et al. Modes of transmission in West Africa: analysis of the distribution of new HIV infections in Ghana and recommendations for prevention: Ghana AIDS Commission. Accra: UNAIDS, 2009. 
37. Nnorom J, Oluwole F, Ogungbemi K, et al. Modes of HIV transmission in Nigeria: analysis of the distribution of new HIV infections in Nigeria and recommendations for prevention: UNAIDS. Nigeria: The World Bank, 2009.

38. Seck K, Lowndes C. Modes de transmission du VIH en Afrique de I'Ouest: analyse de la distribution des nouvelles infections par le VIH en Sénégal: recommandations pour la prévention. Dakar: UNAIDS, 2009.

39. Alarcon J, Pun M, Gutiérrez C, et al. Estimating HIV incidence using the model Modes of Transmission for concentrated epidemics. Lima: Ministerio de Salud, and UNAIDS, 2009.

40. Ministerio de Salud. Modelo para el análisis de la distribución de nuevas infecciones por el VIH en los grupos de exposición y recomendaciones para la prevención. El Salvador: USAID, PASCA, ONUSIDA, 2011.

41. Comisión Nicaragüense del SIDA. Modelo de modos de transmisión del VIH. Analisis de la distribución de nuevas infecciones por el VIH y recomendaciones para prevención. Nicaragua: USAID, PASCA, ONUSIDA, 2012.

42. St Charles 0, Hernandez R, Cuchi P, et al. What do we know? Guyana's modes of transmission study experience. Guyana: UNAIDS Regional Support Team Central and South America, 2012. http://www.unaids.org/en/regionscountries/regions/ latinamerica/ (accessed 18 Oct 2012)

43. Dolores Y, Caballero Vaillant T, Ramirez A, et al. HIV modes of transmission. Analysis of the distribution of new HIV infections in the Dominican Republic and recommendations for prevention. Santo Domingo, Dominican Republic: UNAIDS, Consejo Presidencial del SIDA, Dirección General de Infecciones de Transmisión Sexual y SIDA, 2010.

44. Mumtaz G, Hilmi N, Zidouh A, et al. HIV modes of transmission analysis in Morocco. Morocco Ministère de la santé DELM/PNLS. Weill Cornell Medical College in Qatar, UNAIDS, 2011.

45. Haghdoost A, Douroudi F, et al. Modelling of new HIV infections based on exposure groups in Iran. Iran: Kerman University of Medical Sciences (Knowledge Hub for HIV/AIDS surveillance), UNAIDS, 2011.

46. Scutelniciuc 0, Zohrabyan L, Serbulenco A, et al. Data synthesis on tendencies of the HIV epidemic in the Republic of Moldova 2011. Chisinau: National Center for Health Management, National Center for Public Health, Tiraspol AIDS center, UNAIDS, 2011
47. Republic of Armenia Ministry of Health. HIV prevention response and modes of transmission analysis in armenia in 2011. Yerevan: National AIDS Centre of Republic of Armenia MOH, UNAIDS, 2011.

48. Siripong N, Peerapatanapokin W, Reddy A, et al. Refocusing responses in Asia for impact. Report of the Modes of Transmission Project in Asia: East-West Center, UNAIDS, 2011.

49. Morah E. Status of the epidemic and national response in Kenya. Nairobi, 2006 (unpublished report).

50. Royaume du Maroc Ministère de la Santé, ONUSIDA. Estimation des flux de ressources et de depenses nationales pout la lutte contre le VIH/SIDA. Rabat, Morocco: Direction de l'Epidemiologie et de la lutte contre les Maladies (DELM), ONUSIDA, 2010.

51. WHO, UNAIDS, Unicef. Global HIV/AIDS response: epidemic update and health sector progress towards Universal Access. 2011 Progress Report. Geneva: WHO, 2011.

52. UNAIDS, The World Bank. New HIV infections by mode of transmission in West Africa: a multi-country analysis. Dakar, Senegal: UNAIDS RSTMCA, 2010.

53. Kenya National AIDS Control Council. Kenya National AIDS Strategic Plan, 2009/ 10-2012/13. Delivering on universal access to services. Nairobi: Office of the President, 2009

54. Lo YR, Nguyen TT, Srikantiah P, et al. AIDS in Asia and the Pacific. In: Hall, Hall, Cockerell, eds. HIVIAIDS in the Post-HAART Era. Shelton, CT, USA: People's Medical Publishing House, 2011.

55. Case K, Ghys PD, Gouws E, et al. Understanding the modes of transmission model of new HIV infection and its use in prevention planning. Bulletin of the World Health Organization. In press. http://www.who.int/bulletin/online first/12-102574.pdf (accessed 18 Oct 2012)

56. Mishra S, Sgaier SK, Thompson LH, et al. HIV epidemic appraisals for assisting in the design of effective prevention programmes: shifting the paradigm back to basics. PLOS ONE 2012; 7:e32324.

57. Alary M, Lowndes CM. The central role of clients of female sex workers in the dynamics of heterosexual HIV transmission in sub-Saharan Africa. AIDS 2004;18:945-7.

58. Kontio K. Analysis of HIV prevention response and modes of HIV transmission studies. Outcome evaluation report. 2009. http://www.unaidsrstesa.org/thematic-areas/ hiv-prevention/know-your-epidemic-modes-transmission (accessed 18 0ct 2012). 